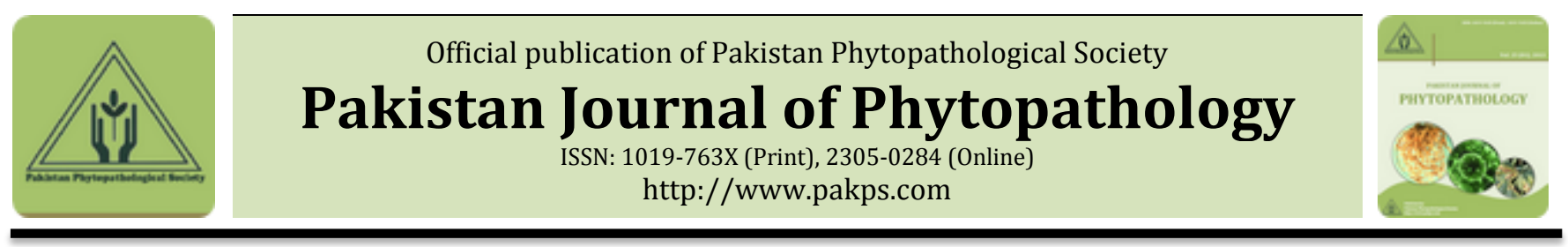

\title{
VARIETAL RESPONSE OF BITTER GOURD GERMPLASM AGAINST MYROTHECIUM RORIDUM TODE EX. FR. CAUSING MYROTHECIUM LEAF SPOT DISEASE AND ITS CHEMOSYNTHETIC MANAGEMENT
}

\author{
aHasnain Sajjad, bMuhammad Iqbal, aAbdul Rehman", aMuhammad W. Alam, bSaira Mehboob, bMuhammad \\ Idrees \\ ${ }^{a}$ Department of Plant Pathology, University of Agriculture, Faisalabad, Pakistan. \\ blant pathology Research Institute, AARI, Faisalabad, Pakistan.
}

\section{A B S T R A C T}

The fungus Myrothecium roridum is the chief hazard to crops including cucurbits inhabit in soil as saprophyte, on diseased plant debris and also as facultative parasite on vegetables, fruits and ornamental plants. Keeping in view the damage caused by $M$. roridum to bitter gourd, screening of nine bitter gourd varieties (BG34F1, Manika 7004, CBT 36, BSS 616, KHBG 037, Leena 7005, Raja, Tipu and C02NO3) was done in Plant Pathology Research Institute, Ayub Agricultural Research Institute Faisalabad under field conditions. All the varieties showed moderately susceptible to highly susceptible reaction ranging between $25-75 \%$ infections on leaves. Significant disease severity was recorded in the genotype Tipu while the lowest disease severity was recorded in the genotype BG34F1. Maximum numbers of flowers were recorded in the variety Tipu (24.33) followed by Raja (17.33) and CO2NO3 (15.33). Maximum number of fruits were recorded in the variety Tipu (40.00) followed by BSS 616 (11.00) and C02NO3 (10.33). M. roridum from the diseased samples was isolated and identified morphologically as white cylindrical conidia with rounded ends under the microscope. In vitro management of the fungus M. roridum was done with fungicides having novel mode of action including Antracol ${ }^{\circledR}$ (Propineb), Cabrio Top ${ }^{\circledR}$ (Pyraclostrobin + Metriam Complex), Nativo ${ }^{\circledR}($ Tebuconazole + Trifloxystrobin), Topsin $\mathrm{M}^{\circledR}$ (Thiophenate Methyl) and Score ${ }^{\circledR}$ (Difenoconazole) at concentrations of $50,100,150,200,250 \mu \mathrm{g} / \mathrm{mL}$ to inhibit the mycelial growth. Among all the fungicides tested, Score significantly reduced the mycelial growth of $M$. roridum with a value of $49 \%$ decrease over control followed by Nativo and Topsin $M$ with a value of $48 \%$ and $47 \%$ respectively. Antracol was found to be the least effective in reducing the mycelial growth of $M$. roridm with a value of $22 \%$ decrease over control.

Keywords: Bitter gourd, Myrothecium leaf spot, varietal response, Difenoconazole, (Tebuconazole+Trifloxystrobin)

\section{INTRODUCTION}

Bitter gourd (Momordica charantia L.) is native to the tropical regions of India and China and currently grown in Asia, South America and East Africa (Yang and Walters, 1992). It is extensively cultivated as a summer vegetable throughout Pakistan on an area of 6107 ha with an annual production of 56949 tons (MNFSR, 2015). The fruit of bitter gourd has a unique bitter taste and considered as a rich source of minerals and vitamins (Desai and Musmade, 1998). In recent years, the crop productivity is going down due

\section{* Corresponding Author:}

Email: rehman.abdul@uaf.edu.pk

(C) 2017 Pak. J. Phytopathol. All rights reserved. to various diseases. Several diseases are known to cause yield losses but leaf spot caused by (Cercospora spp. and Myrothecium roridum), powdery mildew (Sphaerotheca fuliginea), Fusarium wilt (Fusarium oxysporum f. sp. niveum) and downy mildew (Pseudoperonospora cubensis) are worth mentioning (Khan and Kamal, 1962; 1968; Maholay, 1986; Ali et al., 1988). Among all fungal diseases, bitter gourd leaf spot caused by Myrothecium roridum Tode ex Fr has caused severe losses in various bitter gourd producing regions of the world including Pakistan (Costa et al., 2006). The pathogen is a common soilinhabiting fungus with a relatively wide host range that includes agronomic crops including cotton, 
tomato, cacao, coffee, potato, soybean, cucurbits, as well as various ornamental plants (Bharath et al., 2006).

Diseases caused by $M$. roridum are generally thought to be associated most frequently with warmer environments during wet conditions (Fitton and Holliday, 1970). The fungus was first reported to be pathogenic to muskmelons (Cucumis melo) in Texas (McLean and Sleeth, 1961). In Pakistan, M. roridum has been reported to be associated with bottle gourd, sponge gourd, bitter gourd and red gourd (Shaukat et al., 1988; Wahid et al., 1991; Shakir and Mirza, 1992). On bitter gourd leaves, symptoms appeared as tiny circular to irregular water soaked spots turning from yellowish to purplish brown and finally become black in color. As these spots enlarge in size, they merged, covering whole leaf which finally dried out (Shaukat et al., 1988).

Apparently wide range of susceptibility among bitter gourd cultivars in the field has been observed which suggests a moderately elevated level of resistance to Myrothecium leaf spot in some cultivars. Absence of resistance/tolerance against diseases of bitter gourd varieties is supposed to be one of the main reasons for their low yield in Pakistan. Keeping in view the severe damage to bitter guard crop by $M$. roridum, present study was designed to screen out some resistance source of bitter gourd germplasm and in vitro evaluation of fungicides for effective management of M. roridum.

\section{MATERIALS AND METHODS}

Screening of different bitter gourd germplasm against $\boldsymbol{M}$. roridum: Screening of nine different varieties/lines (BG. 34F1, Manika 7004, CBT 36, BSS 616, KHBG 037, Leena 7005, Raja, Tipu, C02NO3) of bitter gourd was done using a 0-5 disease rating scale, where 0 (no symptoms on leaves; highly resistant), $1(<5 \%$ infection on leaves; resistant), $2(5-25 \%$ infection on leaves; moderately resistant), 3(25-50\% infection on leaves; moderately susceptible), 4(51$75 \%$ infection on leaves; susceptible), 5(>75\% infection on leaves; highly susceptible) (Vir and Grewel, 1974), in the research area of Plant Pathology Section, Ayub Agricultural Research Institute Faisalabad. Artificial spray of inoculum was done by grinding the infected leaves of bitter gourd. The experiment was laid out in augmented design by maintaining $\mathrm{P} \times \mathrm{P}$ distance of 1 foot and bed size as $6 \times 6$ feet. Data on total number of flowers and fruits were recorded periodically. Disease severity was calculated by using the following formula given by Rauf et al. (2007).

$$
\text { Disease severity }(\%)=\frac{\text { Sum of all disease rating }}{\text { No. of disease plants }} \times 100 / 5
$$

Isolation, purification and identification of $M$. roridum: Isolations were made from symptomatic leaves of bitter gourd collected from research area of Plant Pathology Section, Ayub Agricultural Research Institute Faisalabad. The diseased samples were brought to Plant Disease Diagnostic Laboratory, Department of Plant Pathology, University of Agriculture Faisalabad for isolation, purification and identification of $M$. roridum associated with diseased samples. Isolation was made following the method of Alam et al., (2017). The samples were surface sterilized in $0.1 \%$ sodium hypochlorite $(\mathrm{NaOCl})$ for 30 $\mathrm{s}$, rinsed three times with sterile distilled water, dried on blotter paper and then placed on potato dextrose agar (PDA) medium in petri plates under laminar flow cabinet. The plates were incubated at ambient temperature of $25^{\circ} \mathrm{C}$. After 3-5 days, mycelia from colonies that emerged from the plated leaf tissues were hyphal tipped and transferred to PDA plates and identification was done based on morphological characteristics of the fungus with the help of available literature (Sutton, 1980).

In vitro efficacy of various fungicides against $\boldsymbol{M}$. roridum: In vitro efficacy of various fungicides including Topsin M, Antracol, Score, Cabrio Top and Nativo was tested against $M$. roridum by using poisoned food technique described by Borum and Sinclair (1968). All fungicides were tested at 50, 100, 150, 200 and $250 \mu \mathrm{g} / \mathrm{mL}$ concentrations. After solidification of PDA, the plates were inoculated by placing $5 \mathrm{~mm}$ discs of 7 days old culture of M. roridum. The experiment was carried out by making three replications of each treatment; the treatment without fungicide served as control. The inoculated plates were incubated at $25^{\circ} \mathrm{C}$ and data on the radial colony diameter was recorded after 5 days of incubation.

\section{STATISTICAL ANALYSIS}

The collected data was analyzed using SAS/STAT statistical software (SAS Institute, 1990). Means were separated using Fisher's protected least significant difference (LSD procedure). Data for disease management was subjected to statistical analysis under completely randomized design with M.STAT 
software for the significance and non-significance of fungicides (Russel and Eisensmith, 1983).

\section{RESULTS}

Percent diseases severity: All the varieties of bitter gourd showed moderately susceptible to highly susceptible reaction against Myrothecium leaf spot (M. roridum) by following disease rating scale of Vir and Grewel, 1974. The data on diseases severity was recorded after $8,9,10$ and $11^{\text {th }}$ weeks of crop sowing and presented in Table 1. Disease severity varied with the plant life cycle phase. After $11^{\text {th }}$ week, maximum mean disease severity was recorded in the genotype Tipu (41.97\%) which was designated as the most susceptible genotype followed by BSS 616 (38.95\%) and KHBG 037 (37.16\%) while the least mean disease severity (27.5\%) was recorded in the genotype BG.34F1. Moreover, when the data of disease severity was subjected to regression analysis (Figure 1), the results revealed that there was a positive correlation between disease progress and weeks in all genotypes except BG34F1 and Leena 7005 which showed negative correlation. The data collected at the $11^{\text {th }}$ week of crop after germination showed the highest values of disease severity.

Table 1. Disease severity of Myrothecium roridum on different lines/ varieties of bitter gourd after 8,9,10 and $11^{\text {th }}$ weeks post inoculation.

\begin{tabular}{|c|c|c|c|c|c|}
\hline \multirow{2}{*}{ Variety } & \multicolumn{4}{|c|}{ Week } & \multirow{2}{*}{ Mean } \\
\hline & 8 & 9 & 10 & 11 & \\
\hline BG34F1 & $25.00 \pm 0.58 \mathrm{i}$ & $25.00 \pm 0.87 \mathrm{i}$ & $30.00 \pm 0.90 \mathrm{gh}$ & $30.00 \pm 0.84 \mathrm{gh}$ & $27.50 \pm 0.83 \mathrm{~g}$ \\
\hline Manika 7004 & $29.16 \pm 0.44 \mathrm{~h}$ & $30.00 \pm 0.84 \mathrm{gh}$ & $40.00 \pm 0.84 d$ & $42.85 \pm 0.61 c$ & $35.50 \pm 1.84 \mathrm{~d}$ \\
\hline СВT- 36 & $30.00 \pm 0.58 \mathrm{gh}$ & $33.30 \pm 0.47 \mathrm{f}$ & $33.30 \pm 0.53 \mathrm{f}$ & $37.50 \pm 0.55 \mathrm{e}$ & $33.53 \pm 0.83 \mathrm{e}$ \\
\hline BSS 616 & $33.30 \pm 0.57 f$ & $37.50 \pm 0.64 \mathrm{e}$ & $40.00 \pm 0.95 d$ & $45.00 \pm 0.95 b$ & $38.95 \pm 1.32 b$ \\
\hline KHBG 037 & $33.30 \pm 0.42 f$ & $35.00 \pm 0.10 \mathrm{f}$ & $37.50 \pm 0.59 \mathrm{e}$ & $42.85 \pm 0.61 c$ & $37.16 \pm 1.11 \mathrm{c}$ \\
\hline Leena 7005 & $25.00 \pm 0.56 \mathrm{i}$ & $31.25 \pm 0.13 \mathrm{~g}$ & $35.00 \pm 0.20 \mathrm{f}$ & $40.00 \pm 0.58 d$ & $32.81 \pm 1.66 \mathrm{e}$ \\
\hline Raja & $25.00 \pm 1.15 \mathrm{i}$ & $26.00 \pm 0.87 \mathrm{i}$ & $28.57 \pm 0.24 \mathrm{~h}$ & $34.37 \pm 0.42 \mathrm{f}$ & $28.48 \pm 1.14 f$ \\
\hline $\mathrm{CO} 2 \mathrm{NO} 3$ & $25.00 \pm 0.98 \mathrm{i}$ & $29.16 \pm 0.49 h$ & $37.50 \pm 0.55 \mathrm{e}$ & $39.28 \pm 0.19 \mathrm{de}$ & $32.74 \pm 1.79 \mathrm{e}$ \\
\hline Tipu & $33.33 \pm 0.41 \mathrm{f}$ & $35.00 \pm 0.20 \mathrm{f}$ & $46.42 \pm 1.05 b$ & $53.12 \pm 1.06 \mathrm{a}$ & $41.97 \pm 2.49 \mathrm{a}$ \\
\hline Mean & $28.79 \pm 0.74 d$ & $31.36 \pm 0.80 c$ & $36.48 \pm 1.04 b$ & $40.55 \pm 1.24 \mathrm{a}$ & \\
\hline
\end{tabular}

Means sharing similar letter in a row or in a column are statistically non-significant $(\mathrm{P}>0.05)$.
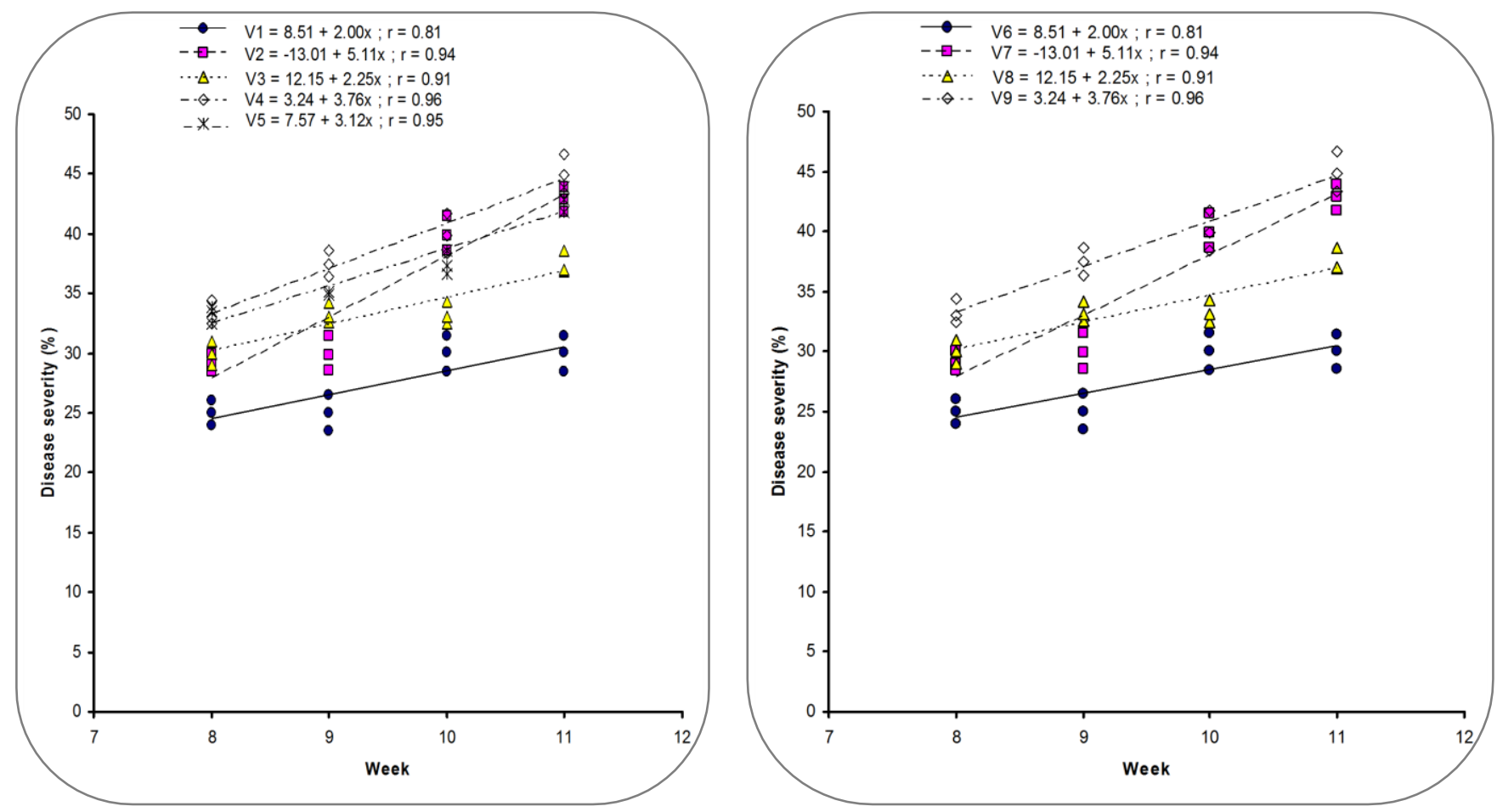

Figure 1. Regression analysis of disease severity on different genotypes (V1 = BG34F1, V2 = Manika 7004, V3 = CBT 36, V4 = BSS 616, V5 = KHBG 037= Leena 7005, V7 = Raja, V8 = C02NO3 and V9 = Tipu) of bitter gourd over weeks. 
Total number of flowers: The data was recorded after 8,9 and $10^{\text {th }}$ week of crop germination. The results indicated that number of flowers was significantly high in all the varieties of bitter gourd. Maximum numbers of flowers were recorded in the variety Tipu (24.33) followed by Raja (17.33) and C02NO3 (15.33) while the total number of flowers was significantly low (7.00) in the variety BG34F1. Maximum 25 flowers were recorded of Tipu cultivar at the $10^{\text {th }}$ week of the bitter gourd crop and minimum 7 flowers were seen on the bitter gourd plant in the $8^{\text {th }}$ week on the KHBG 037 variety. There was no significant difference in the total number of flowers in the different weeks in the variety Leena 7005 (Table 2).

Table 2. Total number of flowers yielded by different varieties of bitter gourd after ten weeks.

\begin{tabular}{lcccc}
\hline \multirow{2}{*}{ Variety } & \multicolumn{3}{c}{ Week } & \multirow{2}{*}{ Mean } \\
\cline { 2 - 4 } & 8 & 9 & 10 & $7.00 \pm 0.71 \mathrm{e}$ \\
BG34F1 & $8.00 \pm 0.58 \mathrm{ij}$ & $5.00 \pm 0.58 \mathrm{k}$ & $8.00 \pm 1.53 \mathrm{ij}$ & $11.33 \pm 1.58 \mathrm{~d}$ \\
MANIKA 7004 & $7.00 \pm 0.58 \mathrm{jk}$ & $10.00 \pm 0.58 \mathrm{ghi}$ & $17.00 \pm 1.73 \mathrm{~d}$ & $10.67 \pm 0.91 \mathrm{~d}$ \\
CBT- 36 & $11.00 \pm 0.58 \mathrm{fgh}$ & $8.00 \pm 0.58 \mathrm{ij}$ & $13.00 \pm 1.73 \mathrm{ef}$ & $11.00 \pm 0.65 \mathrm{~d}$ \\
BSS 616 & $12.00 \pm 0.58 \mathrm{fg}$ & $9.00 \pm 1.15 \mathrm{hij}$ & $12.00 \pm 0.58 \mathrm{fg}$ & $11.00 \pm 1.45 \mathrm{~d}$ \\
KHBG 037 & $7.00 \pm 1.00 \mathrm{jk}$ & $10.00 \pm 0.58 \mathrm{ghi}$ & $16.00 \pm 1.73 \mathrm{~d}$ & $12.00 \pm 0.58 \mathrm{~d}$ \\
LEENA 7005 & $13.00 \pm 0.58 \mathrm{ef}$ & $10.00 \pm 0.58 \mathrm{ghi}$ & $13.00 \pm 0.58 \mathrm{ef}$ & $17.33 \pm 0.91 \mathrm{~b}$ \\
RAJA & $17.00 \pm 0.58 \mathrm{~d}$ & $15.00 \pm 0.58 \mathrm{de}$ & $20.00 \pm 1.73 \mathrm{c}$ & $15.33 \pm 0.76 \mathrm{c}$ \\
CO2 NO3 & $16.00 \pm 1.00 \mathrm{~d}$ & $13.00 \pm 0.58 \mathrm{ef}$ & $17.00 \pm 1.15 \mathrm{~d}$ & $24.33 \pm 1.20 \mathrm{a}$ \\
TIPU & $20.00 \pm 0.58 \mathrm{c}$ & $28.00 \pm 0.58 \mathrm{a}$ & $25.00 \pm 0.58 \mathrm{~b}$ & \\
\hline Mean & $12.33 \pm 0.88 \mathrm{~b}$ & $12.00 \pm 1.24 \mathrm{~b}$ & $15.67 \pm 0.99 \mathrm{a}$ &
\end{tabular}

Means sharing similar letter in a row or in a column are statistically non-significant $(\mathrm{P}>0.05)$.

Total number of fruits: The results regarding total number of fruits indicated that number of fruits on the bitter gourd plants were significantly high in all the bitter gourd varieties. Maximum total number of fruits of bitter gourd was recorded in the variety Tipu (40.00) followed by BSS 616 (11.00) and CO2NO3 (10.33). While the total (Table 3).

Table 3. Total number of fruits yielded by different varieties of bitter gourd after ten weeks.

\begin{tabular}{lccrc}
\hline \multirow{2}{*}{ Variety } & \multicolumn{3}{c}{ Week } & \multirow{2}{*}{ Mean } \\
\cline { 2 - 4 } & 8 & 9 & $9.00 \pm 0.58 \mathrm{hi}$ & $6.00 \pm 0.94 \mathrm{~d}$ \\
BG34F1 & $3.00 \pm 0.58 \mathrm{~lm}$ & $6.00 \pm 1.00 \mathrm{jk}$ & $14.00 \pm 1.15 \mathrm{de}$ & $8.33 \pm 1.56 \mathrm{c}$ \\
MANIKA 7004 & $4.00 \pm 1.15 \mathrm{kl}$ & $7.00 \pm 0.58 \mathrm{ij}$ & $9.00 \pm 1.73 \mathrm{hi}$ & $4.67 \pm 1.31 \mathrm{~d}$ \\
CBT- 36 & $1.00 \pm 0.00 \mathrm{~m}$ & $4.00 \pm 1.15 \mathrm{kl}$ & $13.00 \pm 1.15 \mathrm{def}$ & $11.00 \pm 0.82 \mathrm{~b}$ \\
BSS 616 & $9.00 \pm 1.15 \mathrm{hi}$ & $11.00 \pm 1.15 \mathrm{fgh}$ & $10.00 \pm 0.58 \mathrm{gh}$ & $6.00 \pm 1.19 \mathrm{~d}$ \\
KHBG 037 & $2.00 \pm 0.58 \mathrm{~lm}$ & $6.00 \pm 0.58 \mathrm{jk}$ & $9.00 \pm 1.15 \mathrm{hi}$ & $5.00 \pm 1.12 \mathrm{~d}$ \\
LEENA 7005 & $2.00 \pm 0.58 \mathrm{~lm}$ & $4.00 \pm 0.58 \mathrm{kl}$ & $12.00 \pm 1.15 \mathrm{efg}$ & $9.67 \pm 1.05 \mathrm{bc}$ \\
RAJA & $6.00 \pm 0.58 \mathrm{jk}$ & $11.00 \pm 1.15 \mathrm{fgh}$ & $15.00 \pm 0.58 \mathrm{~d}$ & $10.33 \pm 1.33 \mathrm{~b}$ \\
CO2 N03 & $6.00 \pm 0.58 \mathrm{jk}$ & $10.00 \pm 0.58 \mathrm{gh}$ & $46.00 \pm 1.15 \mathrm{a}$ & $40.00 \pm 2.36 \mathrm{a}$ \\
TIPU & $31.00 \pm 1.15 \mathrm{c}$ & $43.00 \pm 1.15 \mathrm{~b}$ & $15.22 \pm 2.20 \mathrm{a}$ &
\end{tabular}

Means sharing similar letter in a row or in a column are statistically non-significant $(\mathrm{P}>0.05)$.

\section{Cultural and morphological characters of $M$. roridum:}

The colonies were white, floccose, and somewhat raised in the center. Conidia were cylindrical-rod-shaped with rounded ends and measured 4 to $6.5 \times 1.4$ to $2.6 \mu \mathrm{m}$. Conidia formed dark green to black masses on sessile sporodochia in concentric zones (Alam et al., 2017).

Efficacy of various fungicides on mycelial growth of Myrothecium roridum: All the fungicides inhibited the number of fruits were significantly low (4.67) in the variety CBT-36. Maximum 40 fruits were recorded at the Tipu genotype in the $10^{\text {th }}$ week of the bitter gourd crop and minimum 5 flowers were seen on the bitter gourd plant in the $8^{\text {th }}$ week on the two varieties CBT-36 and Leena 7005 (Table 3). 
roridum among all tested fungicides. Maximum mycelial colony of test fungus was recorded in the control which was $2.80 \mathrm{~cm}$. All fungicidal treatments showed reduced Table 4. Effect of various concentrations of fungicides against mycelial growth of Myrothecium roridum after seven days of incubation at $25 \pm 2^{\circ} \mathrm{C}$

\begin{tabular}{|c|c|c|c|c|c|c|c|}
\hline \multirow{2}{*}{ Fungicide } & \multicolumn{5}{|c|}{ Conc. $(\mu \mathrm{g} / \mathrm{ml})$} & \multirow{2}{*}{ Mean } & \multirow{2}{*}{$\begin{array}{c}\text { Percent decrease } \\
\text { over control }\end{array}$} \\
\hline & 50 & 100 & 150 & 200 & 250 & & \\
\hline Antra & $2.13 \pm 0.09 \mathrm{~cd}$ & $1.73 \pm 0.22 \mathrm{fgh}$ & $2.53 \pm 0.03 \mathrm{ab}$ & $2.57 \pm 0.09 \mathrm{ab}$ & $1.97 \pm 0.09 \mathrm{def}$ & $2.19 \pm 0.10 \mathrm{~b}$ & $21.78 \%$ \\
\hline Cabriotop & $2.37 \pm 0.12 b c$ & $1.77 \pm 0.09 \mathrm{fgh}$ & $2.07 \pm 0.09 \mathrm{de}$ & $1.97 \pm 0.15 \mathrm{def}$ & $1.83 \pm 0.18 \mathrm{efg}$ & $2.00 \pm$ & 28. \\
\hline Nativo & $1.50 \pm 0.15 \mathrm{~h}-\mathrm{k}$ & $1.60 \pm 0.12 \mathrm{ghi}$ & $1.50 \pm 0.12 \mathrm{~h}-\mathrm{k}$ & $1.17 \pm 0.12 \mathrm{lhk}$ & $1.53 \pm 0.09 \mathrm{hij}$ & $1.46 \pm 0.06 \mathrm{~d}$ & $47.85 \%$ \\
\hline Topsin M & $1.53 \pm 0.15 \mathrm{hij}$ & $1.53 \pm 0.12 \mathrm{hij}$ & $1.50 \pm 0.06 \mathrm{~h}-\mathrm{k}$ & $1.60 \pm 0.06 \mathrm{ghi}$ & $1.30 \pm 0.06 \mathrm{jkl}$ & $1.49 \pm 0.05 \mathrm{~d}$ & $46.78 \%$ \\
\hline Score & $1.23 \pm 0.07 \mathrm{kl}$ & $1.37 \pm 0.03 \mathrm{i}-\mathrm{l}$ & $1.53 \pm 0.03 \mathrm{hij}$ & $1.53 \pm 0.09 \mathrm{hij}$ & $1.43 \pm 0.09 \mathrm{jkl}$ & $1.42 \pm 0.04 \mathrm{~d}$ & $49.28 \%$ \\
\hline Control & $2.80 \pm 0.00 \mathrm{a}$ & $2.80 \pm 0.00 \mathrm{a}$ & $2.80 \pm 0.00 \mathrm{a}$ & $2.80 \pm 0.00 \mathrm{a}$ & $2.80 \pm 0.00 \mathrm{a}$ & $2.80 \pm 0.00 \mathrm{a}$ & \\
\hline Mean & $1.93 \pm 0.14 \mathrm{a}$ & $1.80 \pm 0.12 \mathrm{a}$ & $1.99 \pm 0.13 a$ & $1.94 \pm 0.14 \mathrm{a}$ & $1.81 \pm 0.13 \mathrm{a}$ & & \\
\hline
\end{tabular}

Means sharing similar letter in a row or in a column are statistically non-significant $(\mathrm{P}>0.05)$.

\section{DISCUSSION}

Myrothecium roridum is a soil borne fungus which continues its life cycle as a saprophyte in dead and decaying plant tissues (Souza-Motta et al., 2003; Castlebury et al., 2004; Costa et al., 2006; Domsch et al., 2007; Quezado et al., 2010). Despite the saprophytic character, M. roridum can cause diseases, mainly in the aerial parts of number of plant hosts, including vegetable crops, fruit plants and ornamentals (Murakami and Shirata, 2005; Domsch et al., 2007). M. roridum has been reported as a pathogen of more than two hundred plant species belonging to distinct botanical families (Quezado et al., 2010). Bitter gourd leaf spot caused by Myrothecium roridum Tode is a serious threat to bitter gourd production in the Punjab province of Pakistan because it has caused considerable losses to farmer community. The pathogen has also been documented as a serious and destructive pathogen causing fruit rot of bitter gourd in India (Sharma and Bhargara, 1978) and leaf spots on watermelon in Korea and Pakistan (Chase, 1983; Kim et al., 2003; Alam et al., 2017). The recent plethora of first reports of $M$. roridum causing disease on plants aforementioned not observed to be susceptible which suggests that either regional change in weather resulting in local growing conditions more conducive to $M$. roridum infection has occurred or an evolution of $M$. roridum sub-species or races has occurred that facilitates a broader host range (Kim et al., 2003; Worapong et al., 2009).

In present studies, all the bitter gourd varieties showed diseased symptoms on leaves invariably. It was observed that all 9 local germplasm screened, showed susceptible to highly susceptible reaction ranging between $25-75 \%$ infections on leaves. The disease growth of $M$. roridum as compared to corresponding control petri plates that were kept free of fungicides treatments (Table 4). severity increased with passage of time. The highest disease severity was recorded in variety "Tipu" with a mean value of disease severity (41.97\%) followed by BSS 616 (38.95\%), KHBG 037 (37.16\%), Manika 7004 (35.50\%), CBT- 36 (33.53\%), Leena 7005 (32.81\%) C02NO3 (32.74\%), Raja (28.48\%), BG34F1 (27.50\%). Our results are in line with already reported results of screening trials. Five commercial cultivars against Myrothecium leaf spot were tested to find out some resistant cultivars against $M$. roridum (Norman, 2003). The results indicated that all the evaluated commercial cultivars showed susceptibility against M. roridum. Sixtyseven indigenous varieties were screened against Myrothecium leaf spot under field conditions (Maji et al., 2009). The findings revealed that 29 varieties out of 67 were susceptible against $M$. roridum.

In present study, genotype "Tipu" yielded maximum number of flowers and fruits among the bitter gourd varieties evaluated. Flower and fruit production had a high variation and thus may be used as representative variables for varietal selection in genomic improvement programs (Ibitoye et al., 2009). The genotype RAJA had the second maximum number of flowers, but it did not result in the maximum production of fruit. This is possibly due to the fact that various cultivars are more sensible to abiotic factors in the propagative phase, such as radiation and temperature. Hot temperatures are responsible for reduction in flowers, low viability, and lead to a lower fruit formation (Pek and Helyes, 2004; Gusmao et al., 2006).

Effectiveness of different fungicides against M. roridum revealed that synthetic fungicides are the most important means to manage diseases (Singh and Sharma, 2007). They are used alone or in combinations 
(Ismail and Zhang, 2004). Different fungicides showed different mode of action. Topsin $\mathrm{M}$ reported to affect wide range of fungi and inhibits fungal tubule function (mitosis structure). Nativo is known as a broadspectrum fungicide, curative with long-lasting protectant activity. It enhanced plant health from the strongest strobilurin in vegetable crops. Score is supposed to be taken up by the plant and acts on the fungal pathogen during penetration and haustoria formation. It stops the development of fungi by interfering with the biosynthesis of sterols in cell membranes. Cabrio Top offers extended residual protection and functions as a preventive fungicide (stopping infection and/or reinfection by prohibiting the germination of fungal spores). Among all the tested fungicides in present studies, Nativo, Topsin M and Score showed statistically meaningful results against $M$. roridum at the concentration of $250 \mu \mathrm{g} / \mathrm{ml}$ while Antracol was least effective against $M$. roridum. Similar findings have been reported in numerous studies. Foliar sprays of fungicides like Topsin M gave maximum efficiency of disease control for M. roridum (87.48\%) on bitter gourd (Sultana and Ghaffar, 2009). Trimiltox forte, Dithane M45 and Pencozeb were effective to inhibit the mycelial growth of $M$. roridum (Ali et al., 1988). Considerable reduction in mycelia growth was observed when the plates were treated with fungicides like iprodione or captan (Chase, 1990). The efficacy of the three fungicides (Trimiltox forte, Topsin M and Pencozeb) was compared to control M. roridum on the seeds of bitter guard and found significant results (Ali et al., 1988; Bharath et al., 2006).

\section{CONCLUSION}

Genotype BG.34F1 showed less disease severity among all the bitter gourd germplasm under study. It could be further used in breeding program to acquire resistance against Myrothecium leaf spot disease. Score showed promising activity by reducing the disease $49 \%$ over control. So this fungicide is a best option for reducing the losses to bitter gourd growers and could be helpful to increase their income.

\section{REFERENCES}

Alam, M. W., A. Rehman, M. Saira, S. Aslam, A. Hameed, S. Sarfraz, S. Muhammad, and K. Riaz. 2017. First report of leaf spot caused by Myrothecium roridum on watermelon in Pakistan. Plant Dis. 101 (6): 1053.
Ali, S., A. Wahid, M. Murtaza and A. Nadeem. 1988. Myrothecium leaf spot of bitter gourd in Pakistan. Pak. J. Sci. and Indus. Res. 9: 598-600.

Bharath, B.G., S. Likesh, B. Yashovarma, H. S. Prakash and H. S. Shetty. 2006. Seed-borne nature of Myrothecium roridum in Watermelon seeds. Res. J. Bot. 1: 44-45.

Bharath, B.G., S. Lokesh, V.R. Rai, H.S. Prakash, K. Yashovarma and 1H.S. Shetty. 2005. Role of foliar spray in the infection biology and management of fungal diseases of watermelon [Citrullus lanatus (Thunb.) Matsum and Nakai]. World J. Agric. Sci. 1: 105-108.

Borum, D.F. and J.B. Sinclair. 1968. Evidence for systemic fungicides protection against Rhizoctonia solani with Vitavax in cotton seedlings. Phytopathology. 58: 976-980.

Castlebury, L.A., A.Y. Rossman, G.H. Sung, A.S. Hyten and J.W. Spatafora. 2004. Multigene phylogeny reveals new lineage for Stachybotrys chartarum, the indoor air fungus. Mycol. Res. 108: 864-872.

Chase A. R. 1990. Controlling Myrothecium petiol rot of Syngonium podophyllum. Proceed. Flo. State Hort. Soc. 103:194-195.

Chase, A.R. 1983. Influence of host plant and isolate source on Myrothecium leaf spot of foliage plants. Plant Dis. 67: 668-671.

Costa, I., P.M. Wanderley, M.A. Cavalcante, M.J. Fernandes and M. Lima. 2006. Hyphomycetes from soil of an area affected by copper mining activities in the State of Bahia, Brazil. Braz. J. Microbiol. 37: 290- 295.

Desai, U.T. and A.M. Musmade. 1998. Pumpkins, squashes and gourds. In! D.K. Salunkhe and S.S. Kadam (eds.), Handbook of vegetable science and technology: Production, composition. Storage and processing. Marcel Dekker, New York. pp. 273-298.

Domsch, K., H.W. Gamsa and T. Anderson. 2007. Compendium of soil fungi. $2^{\text {nd }}$ ed. IHW Verlag. Eching, Germany. 672 pp.

Fitton, M. and P. Holliday. 1970. In: Commonwealth Mycological Institute. Descriptions of Pathogenic Fungi and Bacteria, No. 253, Commonwealth Agricultural Bureau, :1-2.

Gusmao, M.T.A., S. A. L. Gusmao and J.A.C. Araújo. 2006. Produtividade de tomate tipo cereja cultivado em 
ambiente protegido em diferentes substrates. Horti. Brasil. 24: 431-436.

Ibitoye, D.O. P.E. Akin-Idowu and O.T. Ademoyegun. 2009. "Agronomic and lycopene evaluation in tomato (Lycopersicon lycopersicum Mill.) as a function of genotype". World J. Agric. Sci. 5: 892-895.

Ismail, M. and J. Zhang. 2004. Post-harvest citrus diseases and their control outlook, Pest Manage. 15: 29-35.

Khan, S.A and M. Kamal. 1968. The fungi of South West Pakistan. Pak. J. Sci. and Indus. Res. 11: 61-80.

Khan, S.A. and M. Kamal. 1962. Addition to the powdery mildews of Sind region including 13 new records from Pakistan. Pak. J. Sci. Res. 14: 155-156.

Kim, D.K., D.W. Bae, S.C. Lee, K.S. Han and H.K. Kim. 2003. Detection of Myrothecium leaf spot, a new disease of watermelon. Plant Pathol. J. 19: 200-202.

Maholay, M.N. 1986. Seed borne diseases of bitter gourd (Momordica charantia L.). Seed and Farm. 12: 43- 44.

Maji, M.D., H. Sau and B.K. Das. 2009. Screening of mulberry germplasm lines against Powdery mildew, Myrothecium leaf spot and Pseudocercospora leaf spot disease complex. Arch. Phytopath. Plant Prot. 42: 805811.

McLean, D. M. and B. Sleeth. 1961. Myrothecium rind rot of cantaloupe. Plant Dis. 45: 728-729.

MNFSR, 2015. Ministry of national food security and research economic wing, Govt. of Pakistan.

Murakami, R. and A. Shirata. 2005. Mycotoxin B detection from mulberry leaves infected with Myrothecium roridum, cause Myrothecium leaf spot of mulberry, and possible roles in pathogenicity. Japan. J. Phytopath. 71: 91-100.

Norman, D.J., R.J. Henny, J.M.F. Yuen and T.A. Mellich. 2003. Screening for resistance to Myrothecium leaf spot among Syngonium species and cultivars. Hort. Sci. 38: 75-76.

Pek, Z. and L. Helyes. 2004. The effect of daily temperature on truss flowering rate of tomato. J. Sci. Food Agric. 84:1671-1674.

Quezado, D., G.P. Henz, M.L. Paz-Lima, A.R. Medeiros, B.E.C. Miranda, L.H. Pfenning and A. Reis. 2010. New hosts of Myrothecium spp. in Brazil and a preliminary in vitro assay of fungicides. Braz. J. Microbiol.41: 233-240.

Rauf, C.A., M. Ashraf and I. Ahmad. 2007. Management of black scurf disease of potato. Pak. J. Bot. 39: 13531357.

Russel, D.F. and S.P. Eisensmith. 1983. MSTAT-C. Crop Soil Sci. Dept. Michigan State Univ. USA.

SAS Institute, 1990. SAS/STAT Users Guide version 6. SAS Institute, Cary, NC, USA.

Shakir, A.S. and J.H. Mirza. 1992. Seed-borne fungi of Bottle gourd from Faisalabad and their control. Pak. J. Phytopathol. 4: 54-57.

Sharma, N. and K.S. Bharghava. 1978. Fruit rot of bitter gourd. Indian Phytopath. 30: 557-558.

Shaukat, A., A. Wahid, M. Murtaza and A. Nadeem. 1988. Myrothecium leaf spot of bitter gourd in Pakistan. Pak. J. Agric. Res. 9: 598-600.

Singh, D. and R.R. Sharma. 2007. Diseases of fruit and vegetables and their management. In: Prasad, D. (Ed.), Sustainable Pest Manag. Daya Publishing House, New Delhi, India. 12: 311-318.

Souza-Motta, C.M., M.A.Q. Cavalcanti, M.J.S. Fernandes, D.M.M. Lima, J.P. Coimbra and D. Laranjeira. 2003. Identification and characterization of filamentous fungi isolated from the sunflower (Helianthus annus L.) rhizosphere according to their capacity to hydrolyse inulina. Braz. J. Microbiol. 34: 273280.

Sultana, N. and A. Ghaffar. 2009. Pathogenesis and control of Myrothecium spp., the cause of leaf spot on bitter gourd (Momordica charantia Linn.). Pak. J. Bot. 41: 429-433.

Sutton, B.C. 1980. Coelomycetes - Fungi Imperfecti with pycnidia, acervuli and stromata. Commonwealth Mycological Institute, Kew, Surrey, England. 1900 pp.

Vir, S. and J. S. Grewel. 1974. Physiologic specialization in Ascochyta rabiei, the casual organism of gram blight. Ind. Phytopath. 27: 524-526.

Wahid, A., S. Ali and A. S. Shakir. 1991. Seed-borne mycoflora of sponge gourd in Punjab. Pak. J. Agri. Res. 12: 151152.

Worapong, J., J. Sun and G. Newcombe. 2009. "First Report of Myrothecium roridum from a Gymnosperm," North American Fungi. 4:1 -6.

Yang, S.L. and LW. Walters. 1992. Ethnobotany and the economic role of the Cucurbitaceae of china. Econ. Bot. 46: 349-367. 